\title{
Early Warning Techniques for Local Climate Resilience: Smallholder Rice in Lao PDR
}

\author{
Drew Behnke, Sam Heft-Neal, and David Roland-Holst
}

\begin{abstract}
As part of the Regional Rice Initiative Pilot Project, UNFAO has committed resources to support policy dialog and decision capacity related to climate change adaptation and mitigation in agriculture, with particular attention to food security and the rice sector in Asia and the Pacific. This initiative includes sponsorship of research to deliver information and knowledge products for policy makers to better manage climate risks to the rice sector and identify adaptation needs for the rice sector in Lao PDR. In the following pages, we report on progress of one component of this activity, econometric estimation of long term impacts that climate change can be expected to have on rice yields. The work reported here is preliminary and should not in its current form be used as a basis for policy.
\end{abstract}

\section{Introduction}

The report presents a new approach to estimating how climate conditions affect rice production in Lao PDR and modeling the associated potential future impacts of climate change in the rice sector. To conduct our analysis, we use advanced econometric models to estimate the historical relationship between observed rice yields and weather inputs. We then downscale projections from leading climate models to evaluate potential future climate conditions in Lao PDR and implement the econometric models to estimate rice yields under these climate scenarios.

The organization of this report is as follows. First, we provide background and review weather and rice production conditions in Lao PDR as well as summarize the role of weather inputs in rice yields. In addition to average weather conditions,

Originally published by UNFAO as RR Nr. 10-13-1; November 2013

D. Behnke $(\bowtie)$

Department of Economics, University of California Santa Barbara, Santa Barbara, CA, USA e-mail: dbehnke@umail.ucsb.edu

S. Heft-Neal $\bullet$ D. Roland-Holst

Department of Agricultural and Resource Economics, University of California Berkeley,

207 Giannini Hall, Berkeley, CA 94720-3310, USA

e-mail: drwh@berkeley.edu 
special attention is devoted to extreme events such as floods and droughts that can play disruptive roles in rice production. Next we review methodologies used in the literature and discuss the statistical approach employed here in order to estimate the relationship between weather and observed rice yields. Again, we include both average weather and measures of natural disasters in our analysis. Finally, we provide an overview of climate models and apply climate projections to our statistical models of rice yields in order to evaluate potential impacts of climate change on rice yields in Lao PDR.

\section{Background}

The following section provides an overview of rice growing conditions in Lao PDR. Weather inputs, the occurrence of extreme events, and rice production systems are all discussed in order to provide context for the subsequent analysis.

\subsection{Overview of Climate Conditions}

Total rainfall during the rice-growing season in Lao PDR ranges from about 100 $170 \mathrm{~cm}$. However, year-to-year rainfall is highly variable. Moreover, even years with identical levels of total rainfall can have very different growing conditions depending on the pattern of rainfall arrival. Monthly rainfall generally rises each month from the beginning of the growing season until it peaks in August and then decreases thereafter as illustrated in Fig. 1 (both panels).

There is also significant variation in growing season temperatures across Lao PDR. Figure 1 shows the geographical distribution of growing season conditions across space and time. Average minimum (nighttime) temperatures during the growing season range from approximately $20-24{ }^{\circ} \mathrm{C}$, while average maximum (daytime) temperatures range from $28-32{ }^{\circ} \mathrm{C}$. It should be noted however, that these averages mask much of the underlying variability in temperature. For example, average temperature varies across the growing season, where the beginning of the season is typically several degrees hotter than the end of the growing season. Moreover, daily maximum temperatures can exceed $40{ }^{\circ} \mathrm{C}$. Extreme heat, particularly if sustained over several days, puts additional stress on rice growth and may cause large damages (Wassmann et al. 2009b).

\subsection{Extreme Events}

While average climate conditions play an important role in average rice yields, extreme events can cause large impacts that may not be captured by seasonal averages. For example, a year with early season drought and late season floods may 


\section{Rainfall}

500

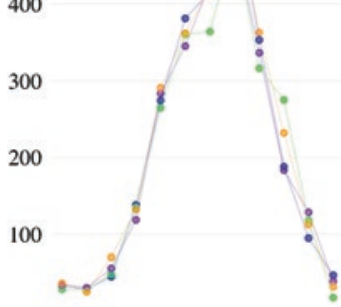

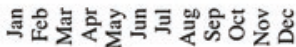

Minimum Temperature

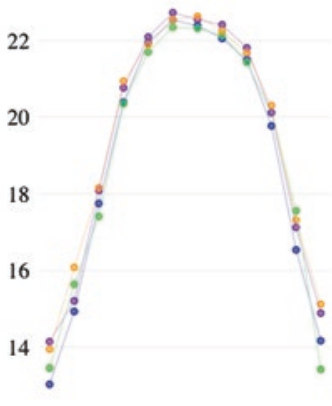

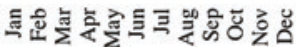

Maximum Temperature

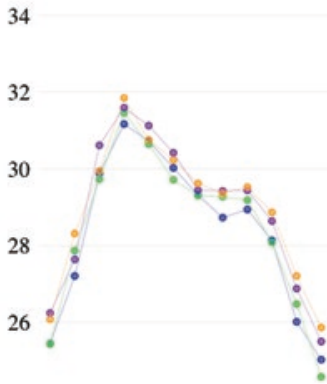

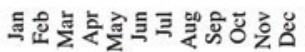

blue $=1970 \mathrm{~s}$, green $=1980 \mathrm{~s}$, purple $=1990 \mathrm{~s}$, orange $=2000 \mathrm{~s}$
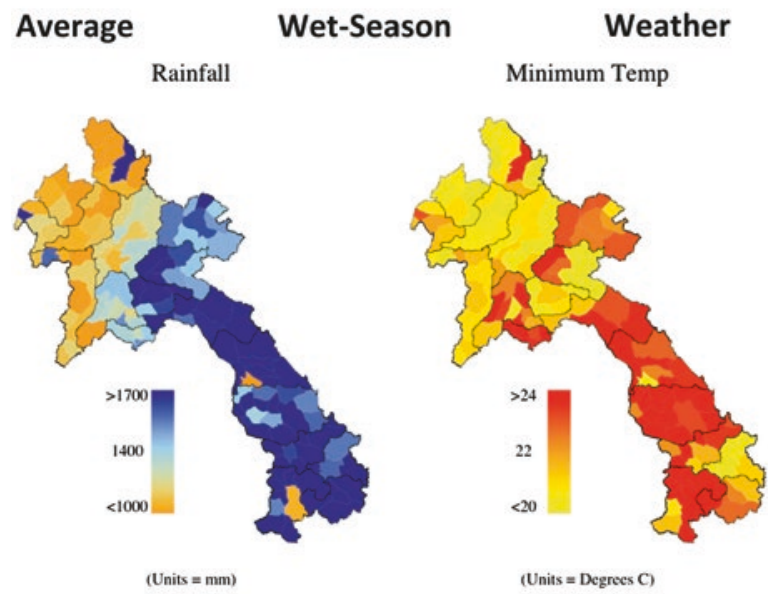

Conditions

Maximum Temp

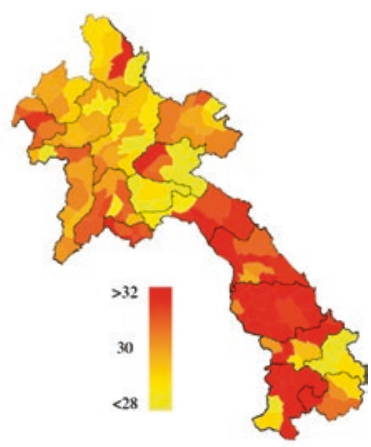

(Units = Degrees C)

\section{Source: $C R U$ (see section 2.2)}

Fig. 1 Decadal changes in seasonal weather conditions (two panels)

record normal growing season rainfall totals while resulting in significant crop damage. Furthermore, rather than contributing to lower annual yields, extreme events may cause the rice planted area to be damaged, resulting in significant loss of the planted crop, which can be devastating to farmer livelihoods. In order to address this important facet of the climate-rice production relationship, we incorporate effects of both average climate and extreme extreme weather events on rice yields.

The majority of rice production in Lao PDR is rain-fed and consequently droughts pose a serious threat. In addition to water shortage, flooding is also a common danger to Lao and other Southeast Asian rice production. In fact, regular 


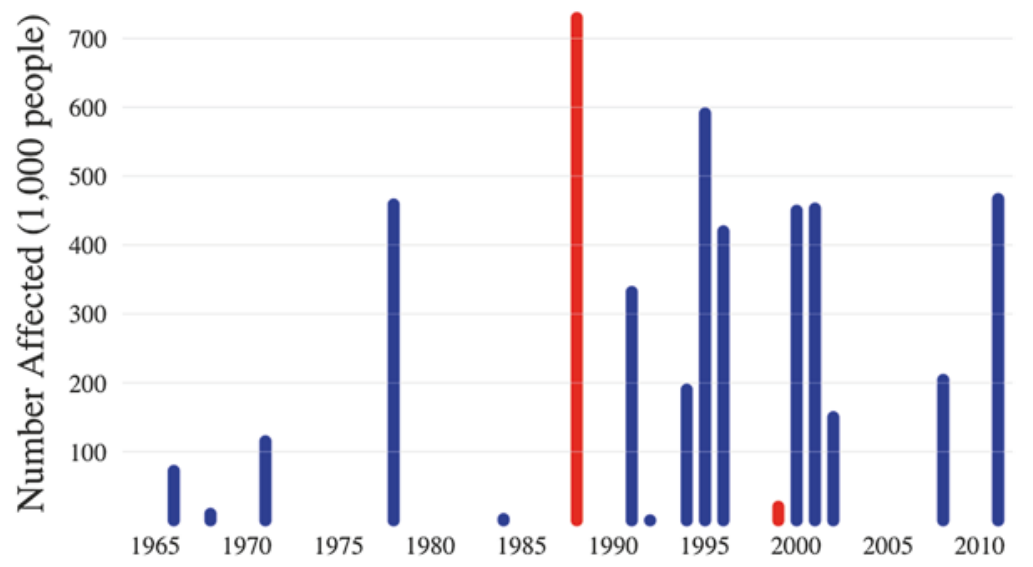

Source: EMDAT database (www.emdat.be)

Fig. 2 Population affected by major flood or drought events in Lao PDR. Blue represents floods and red represents droughts. Note that regional floods and droughts are not included in the figure. Consequently, the figure represents only the largest scale events that have been recorded in this international database of natural disasters

seasonal flooding from the Mekong River is often a greater threat to the central region rice production than water shortages (Schiller et al. 2001).

The toll from extreme flooding and droughts can be significant. Figure 2 displays the estimated number of people affected by major floods and droughts in Lao PDR as recorded in the international natural disaster database EMDAT. ${ }^{1}$ This database provides statistics for the number of people affected by particular large-scale extreme weather events. It should be noted that smaller regional scale events are not recorded in the database and thus not included in the figure. It should also be noted that many of the people affected by these disasters may not be farmers. That being said, farmers are particularly vulnerable to droughts and floods because their livelihoods can be negatively affected. Nonetheless, the EMDAT database provides insight into the potential magnitude of these effects. According to the database, there have been six floods in the last 20 years that affected at least 300,000 people in Lao PDR. Major droughts, although less common than floods, can also exact large damages. In fact, the biggest event in the database is a late 1980s drought that affected more than 700,000 people in Lao PDR.

To address the shortcomings of the EMDAT data we consider the direct impact of flooding and droughts on rice yields in subsequent sections. The data that we use in our analysis, which comes from the Department of Agriculture and is described further in Section 4, is more precise and includes annual damaged rice area for each district that resulted from drought, floods, or pests (Fig. 3).

\footnotetext{
${ }^{1}$ Available online at www.emdat.be.
} 

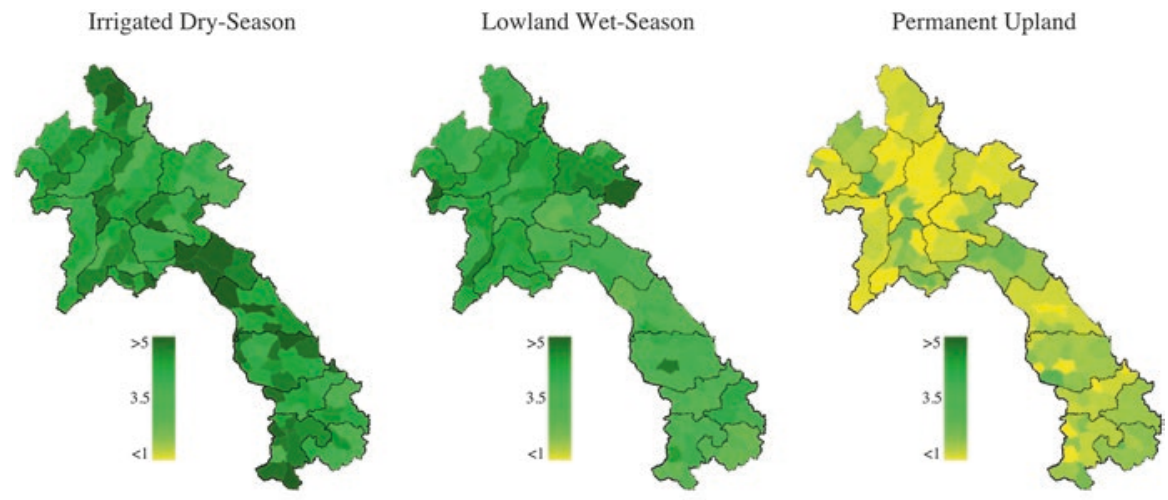

Rotary Upland

Shifting Upland
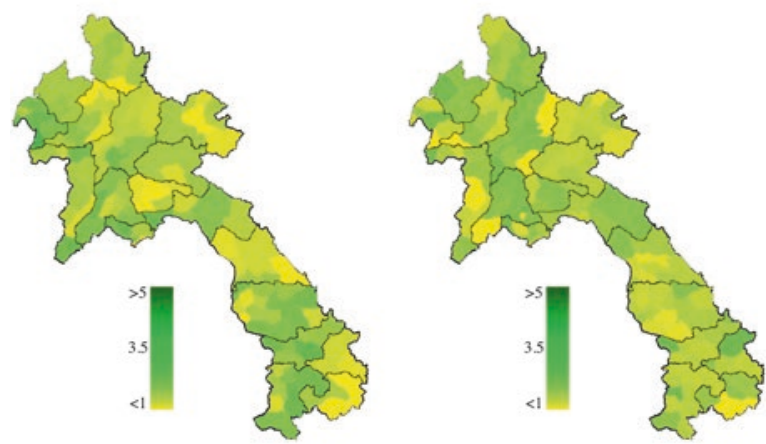

Source: Crop Statistics Yearbook (DOA, Lao PDR)

Fig. 3 Average rice yields. Maps show average rice yields by rice production system. Data cover the period 2006-2012

\subsection{Rice Production}

As a culturally significant, staple food crop, rice has an important role in the economy of Lao PDR. Because of this, the rice production sector has been the focus of various political policies in order to increase production and maintain food security. As a result, Lao PDR has undergone significant transitions in the sector over the past several decades, moving from a net rice importer in the 1970s and 1980s, to a stable and increasing surplus over the last decade.

The introduction of improved seed varieties in the 1970s as well as loosening of price controls in the early 1980 s led to some production increases, but the majority of growth occurred in the 1990s. Over the last 20 years, rice production has more than doubled to reach nearly 3.5 million tones of paddy in 2012 (DOA 2012). This represents an average of $5.1 \%$ annual growth, which is one of the highest in the 
region over this time period. This high growth can be attributed both to the yield improvements (from new, improved seed varieties and increased use of fertilizer) as well as land expansion. Growth from land expansion over the previous two decades can be explained by the steady increase in lowland, rain fed production systems as well as a rapid increase in dry season irrigated production. Concurrently, the lower yield, upland rice production system saw total area steadily fall. Regionally, much of this growth was concentrated in the central plain provinces of Savannakhet, Khammuane, Vientiane, and the Vientiane Municipality as well as the southern province of Saravan. In total, these five provinces comprised $70 \%$ of the total increase in rice production between 1995 and 2010 (MAF 2012).

\subsubsection{Production Systems}

Rice production systems can be categorized into one of five different categories: lowland wet-season, lowland irrigated dry-season, upland permanent, upland rotary, and upland shifting.

Lowland Wet-Season Lowland wet-season is responsible for the majority of production, representing $79 \%$ of the total yield in 2012. This production system is most common in the central and southern regions of the country with $83 \%$ of total yields coming from these areas (DOA 2012). Lowland wet-season production has relatively high yields compared to other production systems with an average of 3.91 tons per ha in 2012. Given the comparatively high yields, and ubiquity of production along the populated Mekong River Valley, lowland wet-season will remain the most important ecosystem for rice cultivation in the foreseeable future.

That being said, lowland wet-season production faces a variety of production constraints. First and foremost, is the constraint from climatic variability, as the production system is reliant on weather inputs for the production process. Rainfall is identified as a particular concern among farmers, as the rainfall pattern can vary from year-to-year, resulting in large fluctuations in production. Furthermore, the permeable nature of the sandy soils that prevail in much of the Mekong River Valley means drought is common occurrence. Temperature is of course an issue as well, as extreme temperature events are known to be harmful to rice production and the random nature of such events means farmers and unable to anticipate temperature shocks (Schiller et al. 2001).

Related to climatic variability, is the problem of insect pests that are rated by farmers as being among the top three production constraints. The relationship between pests, climatic variability, and production is not clearly understood, although it is understood that pests are believed to significantly impact yields and climate plausibly affects the prevalence of pests (Schiller et al. 2001).

Irrigated Dry-Season Dry-season production occurs under irrigated conditions only. During the 1990s, the irrigated dry-season production system saw a rapid increase in production as part of the official national policy to support the continued development of small-scale irrigation schemes. The expansion of the irrigated sys- 
tem was promoted in order to increase national rice production, while at the same time reducing the year-to-year variability associated with wet-season production. Over the 2011-2012 dry-season growing season planted area totaled 108,000 ha representing approximately $11 \%$ of the national crop. Although this is a large increase from the 13,000 ha planted in 1992-1993, it represents only a modest increase from the 87,000 ha planted in 1998-1999. Furthermore, there is a large disparity from the MAF's projected goal of 180,000 ha of production by 2005 (DOA 2012; Schiller et al. 2001).

Due to the intensive nature of irrigated production, the majority of production is concentrated in a few provinces that can support this system. The central region is home to nearly $68 \%$ of the total irrigated dry-season planted area, with production being highly concentrated in the Vientiane Capital and Savannakhet (19\% and 29\% of total area planted respectively). Yields are the highest in this production system with 4.72 tons per ha on average over the 2011-2012 season (DOA 2012). This is unsurprising as the adoption of improved rice production technology is highest in the irrigated areas both as a combination of better extension services and higher farm incomes.

In regards to production constraints, temperature likely plays a larger role for the irrigated production system, as dry-season temperatures are initially cool before dramatically increasing toward the end of the season. Especially of concern are low temperatures in the north where temperatures can fall below $5{ }^{\circ} \mathrm{C}$. In southern and central Lao PDR, the high temperatures during March and April that can coincide with flowering and grain filling are of primary concern (Schiller et al. 2001).

Upland Upland rice cultivation in Lao PDR is split between three production categories; permanent, rotary, and shifting. Estimates vary about the size of these systems, as they are predominantly located in the remote, mountainous northern and eastern regions of the country. Furthermore, due to remote nature of these systems accurate yield measurements are next to impossible. Often upland rice plots are not clearly marked and typically grow in combination with forest trees and other crops. Furthermore, much of the production is in remote areas with limited to no road access and inadequate resources and staff to accurately record yields.

That being said, some estimates for upland production do exist. In the early 1990s it was estimated that 2.1 million ha (or $8.8 \%$ of the national territory) was being used for slash-and-burn cultivation (Schiller et al. 2001). By 2000, it was estimated that about one third of the population still relied on shifting cultivation systems, covering about $13 \%$ of the of the total land area of the country (ADB 2006). In regards to rice production only, official data reports there was 119,000 ha of upland rice planted in 2012 representing approximately $12 \%$ of the total planted area of rice. Of this, approximately $47 \%$ was classified as a permanent upland system (DOA 2012). Furthermore, the DOA reports data on two types of slash-andburn systems referring to them as either "rotary" or "shifting," but has no explicit information on the differences between these systems.

Much like other production systems, there is a strong regional trend in the upland production system. The northern provinces accounted for over $73 \%$ of the total area 
planted, with Luangprabang responsible for $18 \%$ of the total area alone. Yields are low in the upland system and relatively much lower than the other production types with an average yield of 1.8 ton per ha (DOA 2012).

In regards to production constraints, the upland production system has both similar and unique limitations to production. Climatic variability is again a major concern, as farmers must rely on the weather for inputs into production. However, biotic constraints are a much larger concern for the upland system than others. Weeds and rodents were highlighted as the two largest limitations to production for upland farmers (Schiller et al. 2001). Additionally land pressure and pressure for the government have limited production. Traditionally, farmers would clear the forest with fire and after growing rice for a year or two, land would be left to fallow for 10-20 years before returning. However, increased population pressure and land-use restrictions have led to a reduction in fallow periods to as short as 3 years (ADB 2006). Without the necessary time for the land to restore fertility, production is adversely impacted and furthermore such a system is unsustainable ecologically.

\subsubsection{Irrigation}

As previously discussed, irrigation in Lao PDR increased dramatically during the mid-1990s and early-2000s under the government's official policy to expand coverage. During this time, large investments were made to install high-capacity pumps along the Mekong River and its tributaries to expand small-scale irrigation opportunities for smallholders. As a result of the government's expansion efforts, irrigated area increased from about 12,000 ha in 1990 to 87,000 in 1999 , representing a seven-fold increase (Pandey 2001). Growth was even more rapid in the early 2000s, eventually reaching peak coverage of over 500,000 ha in 2006 before declining slightly to the current 400,000 ha of coverage in 2012 (DOA 2012).

\subsection{The Physiological Relationship Between Rice and Weather Inputs}

\subsubsection{The Role of Water}

Rice production, more than most crops, is highly dependent on water availability, both in terms of quantity and timing of application. At some points during the growing season rainfall is highly beneficial, while at other times during the season it can be harmful. Too much or too little rainfall at any stage of rice growth can cause partial or total crop failure (Belder et al. 2004). Excessive water can lead to partial submergence of the rice plant, which reduces yields. In one experiment, Yoshida (1981) reports that $50 \%$ of plant submergence during any of the growth phases led to a $30-50 \%$ reduction in yields. However, while excessive water damages rice crops, drought is widely recognized as the primary constraint for rain-fed rice 
production (Bouman et al. 2005, 2007). Insufficient water causes plant mortality and a wide range of stresses that can lead to spikelet sterility, incomplete grain filling, stunting (Yoshida 1981), delayed heading (Homma et al. 2004), and other adverse yield effects.

Prior to planting, water is also important for rice production as an input to field preparation. In rain-fed production systems, insufficient early rainfall can force farmers to delay planting. Although data in Lao PDR are not available, Sawano et al. (2008) studied the relationship between rainfall and planting dates in rain-fed areas of northeast Thailand, an area that is geographically similar to the central plains of Lao PDR. The authors concluded that, depending on field-level water availability from rainfall, planting dates were locally distributed over an approximately two-month period, while local harvesting took place around the same time everywhere. The implication is obvious - delayed planting from insufficient early season water resources can significantly shorten the growing season and thus reduce output. It remains unclear why farmers who delayed planting did not delay harvest. While the authors did not offer any conclusive answers for this question, they suggested that farmers may not want to delay harvesting in order to prevent interference with subsequent growing seasons, marketing considerations, and other farm and nonfarm activities.

\subsubsection{The Role of Temperature}

Sunlight is another essential input into rice production - rice plants require solar radiation for photosynthesis and heat to promote tissue growth. There are a number of ways to measure energy requirements, the simplest being average temperature. Other related measures include other temperature boundaries (e.g., daily min $\mathrm{T}$, daily max T), agronomic measures such as Growing Degree Days (GDD), and radiation measures.

Generally, extreme highs and lows are of concern to crop growth. However, at the range of temperatures experienced by rice growers in Lao PDR, extreme lows are unlikely to harm rice growth, but extreme highs are a greater threat. ${ }^{2}$ Extreme high temperatures hurt plant growth because it causes heat stress, which delays the growth process (Yoshida 1981; Wassmann et al. 2009b). Furthermore, researchers have highlighted the difference between extreme high nighttime (minimum) temperatures and extreme high daytime (maximum) temperatures. The respiration process appears to make rice plants particularly sensitive to nighttime temperature (Yin et al. 1996). Several studies have highlighted nighttime temperatures as a driving factor of rice growth, where elevated minimum nighttime temperatures greatly reduce rice yields (Yin et al. 1996; Peng et al. 2004; Welch et al. 2010). Using a laboratory experiment to artificially manipulate temperatures, Yin et al. (1996) demonstrate that a one-degree increase in nighttime temperature has a large negative

\footnotetext{
${ }^{2}$ Both daytime (daily maximum) and night-time (daily minimum) extreme highs are potentially harmful to rice yields.
} 
effect on rice yields whereas a one-degree increase in daytime temperature has a slightly positive effect. In fact, across most observed ranges of maximum temperatures, higher daytime temperatures have generally been found to positively affect rice growth (Peng et al. 2004; Welch et al. 2010), however, as temperatures continue to rise, they eventually become harmful. The threshold where maximum daytime temperatures become detrimental to rice growth depends largely on genotype and local growing conditions (including e.g., soils and water availability). For example, depending on genotype and field conditions, Wassmann et al. (2009a) estimated an average cutoff for maximum temperature of $31{ }^{\circ} \mathrm{C}$, beyond which "growth and productivity (yield) rapidly decrease". However, these estimates come from experimental rather than field results, which may not be representative of adaptive, farmer-managed fields where some precautions may be taken when temperatures become potentially harmful. Consequently, if we believe that farmers can effectively ameliorate the effects of extreme temperature through management practices, or through use of local varieties selected for heat resistance qualities, then we might expect observed field data to exhibit higher thresholds.

\section{Analysis I: Estimating the Relationship Between Rice and Climate Change}

This section constitutes the first part of our analysis, where we estimate the relationship between observed historical rice yields and weather conditions in Lao PDR. The following section will use the observed relationship to project yields under potential future climate scenarios. In this we first describe the data and methods used, then describe our primary results. Full model results are presented in tables in the appendix.

\subsection{Methods}

Climate change is a long run phenomenon and it is difficult to distinguish historical climate change from short to medium run weather cycles. In order to estimate potential climate change impacts on agriculture, researchers often estimate the short-term relationship between weather inputs and yields and then apply this relationship over the range of future conditions predicted by climate models. While this approach is imperfect ${ }^{3}$, it allows us to provide an approximate estimate of future climate impacts.

In general, two approaches have been taken to characterize the relationship between weather inputs and rice yields. First, in agronomic studies, usually involv-

\footnotetext{
${ }^{3}$ One needs to be particularly careful about extrapolating current relationships to future unexperienced ranges of climate conditions.
} 
ing laboratory or experimental fields, rice plants are placed under different types of environmental stresses and physiological responses are measured (e.g., Borrell et al. 1997; Homma et al. 2004; Yin et al. 1996). An extension of this approach is to use field data to calibrate crop models that simulate the physiological growth process. Perturbing the inputs in these models can in turn generate predictions of crop growth under potential future climate conditions.

The second approach, which we take here, applies statistical models using plausibly random variations in weather to estimate the effects of weather conditions on observed rice yields. We exploit the presumably random year-to-year variation in temperature and precipitation to estimate whether rice yields are higher or lower in years that are warmer and wetter. With the relationship firmly established, we then use climate projections to model how climate change will affect yields.

In a controlled lab experiment, scientists repeatedly carry out procedures that are identical except for one factor of interest, which is manually manipulated in order to measure the causal impact of said factor on the outcome. As with many social science settings, this type of experiment is not possible for the Lao PDR rice sector. Thus we rely on existing data to demonstrate the impact of historical weather realizations on yields and model the impacts of climate change once this relationship has been established. It should be noted that overall yields have increased over the study period due in large part to technological advances. Consequently, our estimates represent losses with respect to the counterfactual scenario of no climate change. Losses due to climate change do not imply that the yield trends are downward sloping, only that yields have been, and will continue to be, lower in the face of climate change than they would be otherwise. This distinction does not change the fact that climate change has potential to have strongly negative impacts on the rice sector in Lao PDR.

Typically, statistical studies use average growing season (or sub-season) conditions, to represent the weather inputs in the production function. The simplest approach estimates yields (calculated as $\log ($ yield)) as a function of mean temperature, mean precipitation, and their squares. However, several studies have emphasized the differential effects of minimum and maximum temperature (Yin et al. 1996; Peng et al. 2004; Welch et al. 2010), the importance of including radiation (Sheehy et al. 2006; Welch et al. 2010), and the differential effects across phases of the growing season (Welch et al. 2010). In addition, there has been extensive research on water requirements for rice production in irrigated (Bouman et al. 2005, 2007) or rain-fed settings (Xu and Mackill 1996; Sharma et al. 1994; Wade et al. 1999).

Our goal is to provide a localized analysis for Lao PDR. In order to do so, we seek to incorporate the main methods and findings from these disparate sources into statistical models that estimate the impact of climate on rice types grown particularly in Lao PDR. This analysis, in turn, will be used to inform policy prescriptions and identify the production systems and rice growing areas that are most vulnerable to adverse changes in growing conditions. 


\subsubsection{Average Weather Models}

We begin with an approach of estimating the effects of climate on rice yields using a panel regression with a single growing season metric for each weather covariate (average $\min \mathrm{T}$, max $\mathrm{T}$, and precipitation across the growing season). Using average seasonal conditions, we estimate a linear model for each rice production system. These are later used to predict yields under various climate scenarios.

Here, we present a variation of the panel fixed effects (FE) model. This model is an accepted and commonly applied model in the literature (see e.g. Lobell and Burke 2010). Panel data contains repeated observations of the same units over time. In this case we repeatedly observe district rice outcomes. Panel data allows the use of fixed effects, which control for a variety of observations that are unobserved. By conditioning on fixed effects, county specific deviations in weather from the county averages are used to identify the effect of weather on yields. Specifically we chose to control for district and year fixed effects. District fixed effects control for any unobservable characteristic that varies across district but is constant over time. This accounts for important differences across districts such as soil conditions or areas with a higher prevalence of intensive production systems. Year fixed effects control for any unobservable characteristic that varies across years but is constant across all districts. This includes national time trends such as improved technology (irrigation, fertilizer use, or the introduction of improved seed varieties for example).

Within this framework there are a number of choices/assumptions to be made. In each case, there is a tradeoff between controlling for unobserved factors and observing enough variation in the data to be able to make econometric estimations. In reality, we know that there are many factors that affect crop yields, including soil quality, technology, agrochemicals, endogenous behavior, etc. Here, we are only considering the impact of weather, while the other factors are unobserved by us. Thus we are trying to estimate the disaggregated yield impact of weather holding constant other explanatory variables. If district-level time-series data were available on other factors such as agricultural investment, fertilizer use, or pesticides, then we could include these explanatory variables in our model. However, to our knowledge these data do not exist at the required resolution. Fortunately, the fixed effects model attempts to control for these unobserved factors, so that we can still produce unbiased estimates of climate effects. In other words, we can control for a variety of unobserved characteristics but cannot estimate them in our model. We are not attempting to explain every factor that affects yields, but merely to identify the effect of temperature and rainfall. Given our interest is ultimately how yields will change in the face of new climate conditions this does not affect our analysis.

The following reduced form model is our primary empirical specification. In our ideal specification we would have a vector of controls for the other factors that affect yields that we have previously discussed. This would include characteristics such as fertilizer use, pesticide use, soil quality, etc. However, data of this quality does not exist in Lao PDR, which is why we rely on fixed effects. 
Equation 1: Panel Model of Average Weather Effects

$$
\log \left(\mathrm{Y}_{d t}\right)=\gamma_{\mathrm{d}}+\theta_{\mathrm{t}}+\beta_{1} \operatorname{MinT}_{\mathrm{dt}}+\beta_{2} \operatorname{MaxT}_{\mathrm{dt}}+\beta_{3} \mathrm{P}+\varepsilon_{\mathrm{dt}}
$$

$Y_{d t}$ is yield for district $d$ in year t. The model includes district fixed effects $\gamma_{d}$ and year fixed effects $\theta_{t}$. $\beta_{1-3}$ represent the coefficients on our weather variables

One of the fundamental assumptions we have to make is that individual specific time series variation is a valid source of variation for identifying causal effects. In other words, our model assumes that, for each district, weather variation from yearto-year is random. It is obviously not true that weather is random over space (i.e., we expect that some parts of the country to get more rain than other parts every year) but we argue that it is reasonable to assume that deviations from local averages in one year are unrelated to deviations from local averages in the next year.

The modeling approach in equation 1 makes the strong assumption that the effect of weather on yields is the same over different ranges. For example, the linear model assumes an increase in maximum temperature from 29 to 30 has the same effect as an increase from 33 to 34 . This is a very strong assumption and other researchers (Schlenker and Roberts 2009) have found a nonlinear relationship between temperature and yields. Therefore, to add robustness to our analysis we also consider a non-linear model as seen in equation 2 . This model adds square terms for the climate variables used in equation 1 , which allows us to consider if there is a threshold at which the relationship between weather and yields changes. Ideally, we would like to estimate a piece-wise linear model that estimates different slopes over different ranges of covariates. However, given our limited number of observations, a piece-wise model is not advised as it will increase the number of covariates and reduce the necessary power for statistical inference.

\section{Equation 2: Panel Model of Average Weather Effects}

$$
\log \left(\mathrm{Y}_{d t}\right)=\gamma_{\mathrm{d}}+\theta_{\mathrm{t}}+\beta_{1} \operatorname{MinT}_{\mathrm{dt}}+\beta_{2} \operatorname{MinT}_{\mathrm{dt}}^{2}+\beta_{3} \operatorname{MaxT}_{\mathrm{dt}}+\beta_{4} \operatorname{MaxT}_{\mathrm{dt}}^{2}+\beta_{5} \mathrm{P}+\varepsilon_{\mathrm{dt}}
$$

$\mathrm{Y}_{\mathrm{dt}}$ is yield for district $\mathrm{d}$ in year $\mathrm{t}$. The model includes district fixed effects $\gamma_{\mathrm{d}}$ and year fixed effects $\theta_{\mathrm{t}} . \beta_{1-5}$ represent the coefficients on our weather variables

\subsubsection{Modeling Extreme Events}

In addition to modeling the effects of average weather conditions on average rice yields, we can model the effects of drought and floods on rice losses with the same methodology. In equation $2, \mathrm{~L}_{\mathrm{dt}}$ represents rice losses ${ }^{4}$ and $\mathrm{Dr}_{\mathrm{dt}}$ measures drought severity in district $d$ and year $t$. Since our yield measures are annual, drought and

${ }^{4}$ Planted area that could not be harvested. 
flood measures need to be aggregated annually. We will experiment with different aggregation methods.

Equation 3: Panel Model of Extreme Event Effects

$$
\log \left(\mathrm{L}_{\mathrm{dt}}\right)=\gamma_{\mathrm{d}}+\theta_{t}+\beta_{1} \mathrm{Dr}_{\mathrm{dt}}+\beta_{2} \mathbf{X}_{\mathrm{dt}}+\varepsilon_{\mathrm{dt}}
$$

$\mathrm{Y}_{\mathrm{pt}}$ is yield for district $\mathrm{d}$ in year $\mathrm{t}$. The model includes province fixed effects $\gamma_{\mathrm{d}}$ and year fixed effects $\theta_{\mathrm{t}}$. $\beta_{1}$ represents the coefficients on our drought measure. $\mathrm{X}_{\mathrm{dt}}$ are other controls.

\subsection{Data}

\subsubsection{Rice Yields}

Our rice yield data for Lao PDR come from the "Crop Statistics Year Book" published by the Department of Agriculture (DOA) within the Ministry of Agriculture and Forestry (MAF). These reports contain a wide variety of detailed crop production data at the district level and have been published annually since 2005 . Unfortunately, rice production data before 2005 in Lao PDR is limited to province level aggregates that are of little use to our analysis, and district level rice production data is only available from 2005 through 2011. Although our panel is limited, it represents the most accurate and detailed rice production data in existence for this country. Rice production data is split between the five distinct production systems used in Lao PDR and these contain a variety of important statistics useful to our analysis. The variables in the data include planted area, harvested area, yield, and damaged area by source (drought, flood, etc).

\subsubsection{Weather Conditions}

It is inherently difficult to measure weather over space. Weather is observed at individual weather stations, and ideally want to have weather stations collecting data every few meters in order to capture variation in conditions over space. Of course, managing so many weather stations is impractical, and instead observed values are interpolated over locations in between weather stations. There are many different forms of weather data sets that have carried out this interpolation over different spatial and temporal resolutions. Each data set has its own advantages and drawbacks. Here we carry out our analysis with two separate weather data sets, known by the acronyms CRU and APHRODITE, described below. CRU data provide more weather variables (i.e., MIN, MAX) but at a lower temporal and spatial resolution. By including two completely different weather data sets we decrease the likelihood that our results will rely on the peculiarities of a particular data set. 
The first weather data come from the Climatic Research Unit (CRU) at the University of East Anglia. The research group produces several global data products that include monthly average minimum (nighttime) temperature, maximum (daytime) temperature, mean temperature, and monthly total rainfall. We utilize the high-resolution gridded data $\operatorname{sets}^{5}$ that have a resolution of $0.5 \times 0.5$ degrees globally. This translates to approximately $55 \times 55 \mathrm{~km}$ at the equator. Each Lao PDR district is overlapped on the grid and area weighted averages are calculated in order to estimate monthly weather conditions for each district over the sample period.

The second data set, APHRODITE 6 , is described by Yatagai et al. (2012). Researchers in Japan utilized a high density cluster of proprietary station data in order to create a high-resolution data set that includes daily average temperature and daily rainfall at a resolution of $0.05 \times 0.05$ degrees $(\sim 5 \times 5 \mathrm{~km})$. Although daily temperatures are useful, this data set does not contain minimum and maximum temperature information, and covers only Asia.

\subsubsection{Extreme Events}

\section{Droughts}

Although difficult to measure from seasonal rainfall and temperature data, researchers have begun to use remote sensing data from satellites to estimate drought severity. In the present analysis, we utilize a new measure developed by Mu et al. (2013) called the Drought Severity Index (DSI). Mu and colleagues produce global DSI measures from satellite data covering the globe averaged over eight day periods from 2000 through 2011 at a resolution of $0.05 \times 0.05$ degrees $(\sim 5.5 \times 5.5 \mathrm{~km})$. In theory, DSI values range from negative infinity to positive infinity, however, in practice most values are clustered around zero. Negative DSI values signify drier-thannormal conditions while positive values signify wetter than normal conditions. A zero value for DSI implies normal conditions. While it is an imperfect measure, DSI allows us to estimate district level drought severity across the rice-growing season and therefore estimate the effects of droughts on rice losses. Moreover, the drought patterns suggested by the DSI appear to be consistent with precipitation patterns observed in other data sets.

\section{Floods}

Like droughts, measuring flood extent is a practical difficulty that we address by using remotely sensed satellite data processed to estimate standing water extent. As far as the authors know, there are no available global remotely sensed flood measures. Consequently, as a second best option, we utilize DSI as a flood measure

\footnotetext{
${ }^{5} \mathrm{http}: / / \mathrm{www} . c r u \cdot u e a \cdot a c . u k /$ data.

${ }^{6}$ http://www.chikyu.ac.jp/precip/products/index.html.
} 
where large positive values for DSI imply flooding. The developers of DSI note that flood measurement is a potential extension of DSI, but also caution that DSI has not been fully evaluated as a flood measure. Consequently, we proceed with caution using the best available flood measures to estimate the impact of flooding on rice production.

\subsubsection{Data Limitations}

There are significant constraints on data availability (and, inevitably, quality) for Lao PDR. First and foremost, detailed rice production statistics have only begun to be collected in recent years. Therefore, although we have a more than 40-year panel for weather, our analysis is limited given extreme constraints on availability of rice production statistics. For example, the small number of observations makes it difficult for us to detect non-linearities in the weather-rice relationship. That being said, the DOA has done an excellent job of identifying the data shortcomings, and there appears to be a serious effort underway to improve data availability across the country. Therefore, we believe that despite having a limited panel, this represents the single best quality data currently available.

We have also been unable to locate other data that would have improved our analysis. We hoped, for example, to obtain rice crop calendar information on the length of growing period for each district in the country, but no data like this currently exists. The closest data of use came from the National Agricultural and Forestry Research Institute (NAFRI), which had crop calendar information for just a single province, based on their own recent field study. Although this is of value, we do not incorporate into this analysis as we model yields for the entire country, which has diverse geographical regions and growing climates. Another potential area of further exploration we hoped to explore was the affect of changes on rice yields on different socio-economic variables. In order to examine this however, we would need access to the Lao Expenditure and Consumption Survey (LECS), which has been conducted every five years since 1997/98.

Given the serious data concerns over the quality of upland rice production data we chose to omit upland production from our analysis. Data collection in Lao PDR suffer from imperfect systems and data collection is often a highly political issue. Reliable data on yields at the district level require a dedicated support staff and systems in place to ensure accurate reporting. Furthermore, upland production faces a variety of constraints that severely limit the accuracy of data collection. Considering these issues, we instead focus our analysis on lowland systems where data quality is believed to be much higher. 


\subsection{Results}

Consistent with previous statistical studies (e.g., Peng et al. 2004; Welch et al. 2010), the preliminary results of our linear fixed-effects regression model of average weather (equation 1) suggest that elevated minimum nighttime temperatures ${ }^{7}$ are highly damaging to rice yields as seen in Table 1. With regards to different production systems we find these trends are largely similar, although varying in their severity and significance. For lowland rain-fed production we find that that a 1-degree rise in the nighttime temperature reduces rice yields by $4.6 \%$ holding all else constant. Although this result is not statistically significant at conventional levels it is consistent with results from previous studies that suggest an increase in average nighttime temperature leads to reduction in yields. Given the limited amount of data and associated low statistical power, non-significant effects are unsurprising. Looking at daytime temperatures, we find that a 1-degree rise in temperature increase yields by $11.8 \%$ holding all else constant, and these effects are significant at the $10 \%$ level. Based on this evidence, this might suggest that increasing temperatures could have an overall positive impact on rice yields for the most important and common rice production system in the country. Furthermore, we find statistically significant evidence that increases in precipitation increase yields, although the effect is very small. We show that increasing precipitation by $1 \mathrm{~cm}$ over the growing season increases yields by approximately $0.1 \%$ holding all else constant.

We find that changes in temperature appear to have no effect on yields for irrigated dry season production. This might be suggestive of the fact that irrigated

Table 1 Impact of weather on $\log$ rice yields, district level, 2006-2011

\begin{tabular}{|c|c|c|}
\hline & (1) & (2) \\
\hline & $\begin{array}{l}\text { Dry } \\
\text { season }\end{array}$ & Wet season \\
\hline \multirow[t]{2}{*}{ Min temperature } & 0.045 & -0.046 \\
\hline & $(0.028)$ & $(0.038)$ \\
\hline \multirow{2}{*}{$\begin{array}{l}\text { Max } \\
\text { temperature }\end{array}$} & -0.013 & $0.118^{*}$ \\
\hline & $(0.053)$ & $(0.066)$ \\
\hline \multirow[t]{2}{*}{ Precipitation } & $-0.001^{* *}$ & $0.001^{* * *}$ \\
\hline & $(0.000)$ & $(0.000)$ \\
\hline Mean log-yield & 1.530 & 1.277 \\
\hline No obs & 578 & 683 \\
\hline $\mathrm{R}^{2}$ & 0.691 & 0.732 \\
\hline
\end{tabular}

Standard errors in parentheses

Significance levels indicated by $* 0.1, * * 0.01$, $* * * 0.05$

\footnotetext{
${ }^{7}$ For the purpose of this study, minimum nighttime temperature is defined as the lowest temperature recorded by weather stations at night. Some stations record several observations per night while other stations record a single nighttime observation.
} 
Table 2 Non-linear impact of weather on $\log$ rice yields, district level, 2006-2011

\begin{tabular}{l|l|l}
\hline \multirow{2}{*}{ Min temperature } & $(1)$ & $(2)$ \\
\cline { 2 - 3 } & $\begin{array}{l}\text { Dry } \\
\text { season }\end{array}$ & Wet season \\
\hline \multirow{2}{*}{ Min temperature square } & -0.099 & $1.007^{*}$ \\
\cline { 2 - 3 } & $(0.481)$ & $(0.427)$ \\
\cline { 2 - 3 } Max temperature & 0.003 & $-0.024^{*}$ \\
\hline Max temperature & 0.0149 & $(0.010)$ \\
\cline { 2 - 3 } square & $(0.692)$ & -0.490 \\
\hline Precipitation & -0.004 & $0.0138)$ \\
\cline { 2 - 3 } & $(0.011)$ & $(0.005)$ \\
\hline Mean log-yield & $-0.000^{* * *}$ & $0.000^{*}$ \\
\hline No obs & $(0.000)$ & $(0.000)$ \\
\hline $\mathrm{R}^{2}$ & 1.530 & 1.277 \\
\hline \multirow{2}{*}{ Signify } & 578 & 683 \\
\hline & 0.691 & 0.739 \\
\hline
\end{tabular}

Significance levels indicated by $* 0.05, * * 0.1, * * * 0.01$

production systems are typically market oriented, intensive systems, and thus farmers are better able to withstand extreme temperature events. However, we find there is a small effect that increased precipitation decreases yields in the dry season.

In regards to the non-linear approach modeled in eq. 2, we find some evidence that there is a non-linear relationship between temperature and yields as seen in Table 2. For lowland rain-fed production, we find that elevated nighttime temperatures improve yields up to approximately $21^{\circ} \mathrm{C}$, after which increased nighttime temperatures reduce yields. Given that the average minimum temperature across our sample is greater than $21^{\circ} \mathrm{C}$, we see the large negative effect in Table 1. For daytime temperatures we find weak evidence of the opposite effect. The results in Table 2 suggest that elevated daytime temperatures decrease yields until approximately $24.5^{\circ} \mathrm{C}$, after which they have a positive effect. Once again, average daytime temperatures are above $24.5^{\circ} \mathrm{C}$, which adds robustness to the effect we find in Table 1 .

\subsubsection{Evaluating the Model}

While the results are broadly consistent with previous studies (i.e., negative coefficients on minimum temperature, positive coefficients on maximum temperature), limited data sources mean that our analysis may lack sufficient power to precisely identify these effects. Consequently, many of the coefficients are not statistically significant. The $\mathrm{R}^{2}$ and adjusted $\mathrm{R}^{2}$ are generally similar to studies carried out in other settings, if not slightly lower here.

As a robustness check, we also estimated Equation 1 for provincial level rice yields from 1990 through 2008 as seen in Table 4. These data represent all rice types across all growing seasons and comes from the IRRI World Rice Statistics database. 
Table 3 Rice area, production, and yield (2012)

\begin{tabular}{l|l|l|l}
\hline Region/province & Area $(\%$ of total) & Production $(\%$ of total) & Yield \\
\hline A. Northern & $\mathbf{2 1 . 5 5}$ & $\mathbf{1 8 . 9 1}$ & $\mathbf{3 . 2 6}$ \\
\hline Phongsaly & 1.98 & 1.50 & 2.81 \\
\hline Luangnamtha & 1.78 & 1.78 & 3.7 \\
\hline Oudomxay & 2.62 & 2.21 & 3.13 \\
\hline Bokeo & 2.76 & 2.70 & 3.63 \\
\hline Luangprabang & 3.91 & 2.63 & 2.51 \\
\hline Huaphanh & 3.21 & 2.83 & 3.28 \\
\hline Xayabury & 5.28 & 5.27 & 3.7 \\
\hline B. Central & $\mathbf{5 2 . 6 3}$ & $\mathbf{5 4 . 1 8}$ & $\mathbf{3 . 8 5}$ \\
\hline Vientiane Municipality & 8.14 & 9.82 & 4.49 \\
\hline Xiengkhouang & 3.16 & 3.04 & 3.58 \\
\hline Vientiane & 7.10 & 7.76 & 4.12 \\
\hline Borikhamxay & 4.69 & 4.60 & 3.79 \\
\hline Khammuane & 7.61 & 7.30 & 3.56 \\
\hline Savannakhet & 21.92 & 21.66 & 3.67 \\
\hline Xaysomboun & 25.82 & 26.92 & 3.91 \\
\hline C. Southern & $\mathbf{9 . 3 2}$ & $\mathbf{8 . 7 4}$ & $\mathbf{3 . 5 1}$ \\
\hline Saravan & 1.18 & 1.09 & 3.43 \\
\hline Sekong & 12.74 & 15.07 & 4.45 \\
\hline Chmpasack & 2.58 & 2.02 & 2.91 \\
\hline Attapeu & 21.55 & 18.91 & 3.26 \\
\hline Source DOA 2012 & &
\end{tabular}

Source: DOA 2012

Table 4 Impact of weather on $\log$ rice yields, province level, 1990-2008

\begin{tabular}{l|l}
\hline & $(1)$ \\
\hline \multirow{2}{*}{ Min temperature } & $-0.074^{*}$ \\
\cline { 2 - 2 } & $(0.032)$ \\
\hline Max temperature & $0.052^{* *}$ \\
\cline { 2 - 2 } & $(0.025)$ \\
\hline Precipitation & $0.000^{* *}$ \\
\cline { 2 - 2 } & $(0.000)$ \\
\hline Mean log-yield & 7.89 \\
\hline No obs & 337 \\
\hline $\mathrm{R}^{2}$ & 0.854 \\
\hline Adjusted $\mathrm{R}^{2}$ & 0.836 \\
\hline
\end{tabular}

Significance levels indicated by $* 0.01, * * 0.05, * * * 0.1$

Standard errors in parentheses

The results are displayed in the appendix. With the IRRI provincial data, all coefficients are found to be statistically significant and the $\mathrm{R}^{2}$ values are significantly higher. This exercise suggests that a longer time series may provide more power to estimate these relationships relative to a larger cross-section. 


\section{Analysis II: Projecting Future Rice Production Under Climate Change}

\subsection{Climate Projections}

The Intergovernmental Panel on Climate Change (IPCC 2007a) predicts that Southeast Asia will experience warmer temperatures, increased frequency of heavy precipitation, increased droughts, and lower annual levels of rainfall in the next century. Changes in the climate are most likely to affect Lao rice yields through harmful extreme temperatures, reduction in water availability from lower levels of rainfall, and a reduced growth period attributed to higher temperatures and radiation levels. Rice in Lao PDR is presently grown at the upper end of the optimal temperature range for rice production. This suggests that Lao rice production is likely to be harmed if future temperatures rise as expected (Wassmann et al. 2009b).

On a global scale, researchers estimate that minimum temperatures have risen faster than maximum temperatures over the last century. Easterling et al. (1997) dissects the trend of increasing diurnal temperatures and attributes it to increased $\mathrm{CO}_{2}$ concentration in the atmosphere. However, in our data set we observe maximum temperatures rising faster than minimum temperatures in the last 30 years. For more detailed predictions of future conditions we turn to the Global Climate Models (GCM) published by the IPCC.

Overview of Global Climate Models (GCMs) GCM $^{8}$ are mathematical models used to simulate the dynamics of the climate system including the interactions of atmosphere, oceans, land surface, and ice. They take into account the physical components of weather systems and use these relationships to model future climate conditions. While there are high levels of uncertainty involved in GCMs, these models can help provide insights into future climate scenarios.

The IPCC serves as a central organization for research groups around the world to submit their models. Each research group must choose an approach to modeling physical climate interactions, spatial and time resolutions, and future economic conditions, among other things. Variation in model choice can result in a wide variety of predictions. Fortunately, the IPCC has attempted to standardize economic/emissions scenarios in order to increase comparability across models. However, while these scenarios limit the choices that modelers are faced with, there are still many assumptions to be made about how to model future climate. Differences in these choices result in a still wide variation in predictions across models, even within economic scenarios.

In order to improve comparison across GCMs from different research groups across the world, the IPCC publishes baseline greenhouse gas emissions scenarios, the most recent of which is called the Special Report on Emissions Scenarios (SRES), for all groups to utilize. Here we use three of the baseline scenarios established in the IPCC Fourth Assessment Report (AR4), published in 2007 (IPCC 2007b).

\footnotetext{
${ }^{8}$ Also referred to as Global Circulation Models with the same acronym.
} 
The B1 scenario depicts increased emphasis on global solutions to economic, social, and environmental stability, but without additional climate initiatives. It assumes rapid global economic growth, but with changes toward a service and information economy with a population rising to 9 billion in 2050 and then declining thereafter. Clean and resource efficient technologies are introduced limiting future emissions. This scenario estimates an increase in global mean temperatures of $1.1-2.9^{\circ} \mathrm{C}$ by 2100 .

The A1B scenario also assumes global economic growth and a more homogenous future world but with less global emphasis on the information and service economy. Instead, it assumes a continuation of current economic activities, but with more efficient technologies and a balanced emphasis on all energy sources. It assumes similar population increase to 2050 , followed by a decline in global birth rates. This scenario predicts, on average, a $2-6{ }^{\circ} \mathrm{C}$ warming of global temperatures by 2100 .

The A2 scenario depicts a more heterogeneous world with uneven global economic develop and an emphasis on self-reliance and preservation of local identities. Fertility patterns across regions converge slowly, resulting in a continuous increase in global population. Economic development is regionally fragmented and there is less global cooperation. This scenario predicts a global increase in temperature of $2-5.4^{\circ} \mathrm{C}$ by 2100 .

\subsubsection{Selecting GCM Models}

It is unclear whether any one model is more 'valid' than others (Burke et al. 2015). However, some argue that models have different strengths and weaknesses and should thus be carefully selected for specific applications (e.g. Knutti et al. 2010). While many studies choose one (or a few) models, and make predictions based on those scenarios, it is unclear how one would select the 'best' model. To add to these difficulties, different models offer widely different future predictions of climate conditions. Consequently, predicted future yields will depend highly on which GCM is utilized to forecast future climate conditions. For the time being, we follow the recommendations made by Burke et al. (2015) and include as many models as possible with equal weights on the outcome predicted by each model. Our reasoning is that policy recommendations should be informed on the range of possibilities. However, by using many models the range of predicted outcomes can vary widely. Nonetheless, we argue that the alternative of counting on the predictions of one model underrepresents the uncertainty involved in predicting effects of future climate change, and that it would be unwise to make policy recommendations based on a single model. Instead, we incorporate predictions from the 14 models that offer predictions for our variables of interest (min temperature, max temperature, precipitation) under three economic scenarios (A1B, A2, B1). In total, we therefore have 42 future climate scenarios, one for each model-scenario pair, each of which can be evaluated for a range of time frames. Finally, we can calculate the yield outcomes under each of these scenarios and the median outcomes for each economic scenario represent our estimates for future yields assuming low, medium, or high emissions in the future. 


\subsubsection{Downscaling Methods}

For each model-scenario combination we first calculate the model estimated monthly average weather conditions ( $\mathrm{min} / \mathrm{mean} / \mathrm{max}$ temperature and precipitation) over the previous decade (2000-2010) for each district. We do this by matching each district to the four closest GCM grid cells and then weighting each GCM cell by the inverse distance of the center of the GCM cell to the center of the district where weights are forced to sum to 1 . This provides us with a historical standard by which to measure future projections. Next, future period monthly averages are calculated for each decade up to 2050. Future average monthly conditions are then related back to the GCM estimated historical conditions for the 2000-2010 period to provide predicted climate change. Temperature changes are calculated as an absolute degree change in monthly averages while precipitation change is calculated as percentage change in average millimeters of rainfall per month.

Once we have estimated future changes in absolute (temperature), or percentage absolute (precipitation) terms, we add the predicted changes to the estimated historical data for each district, with changes separated by month. Once we have calculated historical conditions under climate change, we use our model to predict yields under the climate change weather conditions.

This process is repeated for all 42 model-scenario combinations (14 models, 3 scenarios) and the median outcomes are reported as the predicted yield changes under climate change for each decade. Although computationally tedious, incorporating 14 models provides a more representative range of possible future climate conditions, and of the high levels of uncertainty associated with predicting future climate. This issue is discussed in detail below.

\subsubsection{Climate Projections for Lao PDR}

Time-series of the climate projections for Lao PDR are displayed in Fig. 4. On average, growing season temperatures are predicted to increase approximately $1{ }^{\circ} \mathrm{C}$ by 2050 while growing season rainfall is expected to slightly decrease. However, some GCMs predict an increase in growing season rainfall over this period.

\subsection{Yield Projections}

\subsubsection{Methods}

In order to evaluate potential climate risk to rice production, we use our rice models to predict yields under future climate scenarios. Due to the resolution of our data, we are able to predict yields at the district level. We estimate future yields by using our estimated statistical model to predict yields at the values of weather variables 


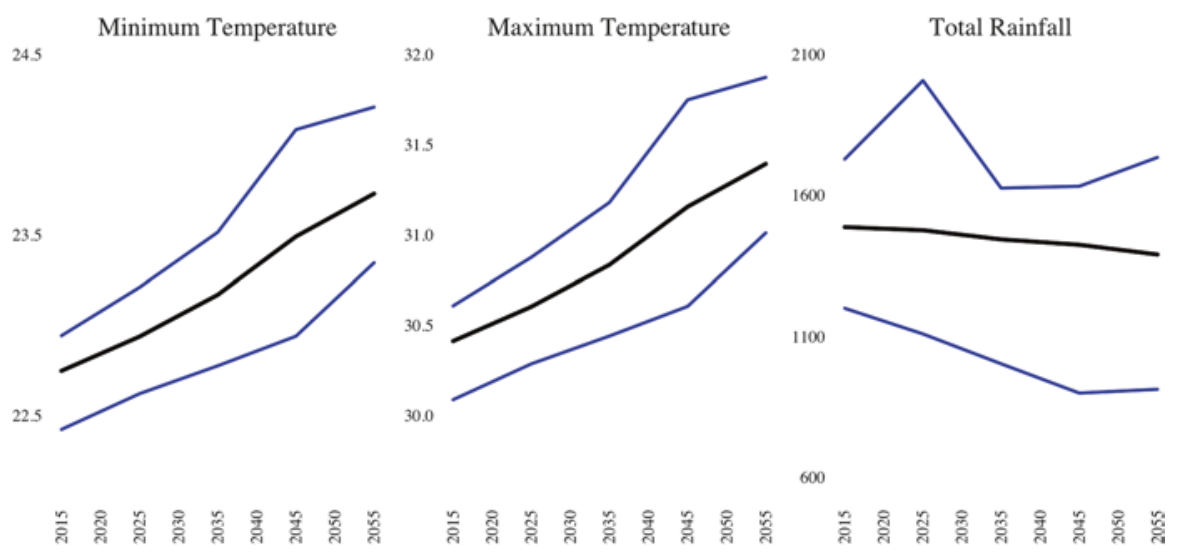

Fig. 4 Forecast climate conditions across 14 GCMs. Average growing season climate conditions forecast up to 2055. The black line represents the median value across 14 GCMs. The blue lines represent the minimum and maximum values across GCMs

predicted by the climate model. In order to remain consistent, we use the same approach to estimate yields over the study period (i.e., the 2000s) and then calculate yield changes relative to this baseline.

Quantifying Uncertainty with Yield Projections There are two primary types of uncertainty associated with making yield-climate projections. First, there is uncertainty associated with our statistical models. Our models are linear approximations of the yield-weather relationship and thus are best suited to predict how yields respond to perturbations in weather variables only over the observed range of conditions. Fortunately, this type of uncertainty is quantifiable through standard errors and other measures such as Root Mean Squared-Error calculated by using our model to predict observed yields. The second type of uncertainty arises from unpredictability of future climate conditions. GCMs attempt to predict future conditions, however, the uncertainty associated with these predictions far exceeds the statistical uncertainties discussed above. In fact, simulations have shown that uncertainty arising from climate projections outweighs statistical uncertainty by several orders of magnitude (Burke et al. 2015). Quantifying model uncertainty is less straightforward. Here we follow the approach suggested in Burke et al. (2015) and use variation across yield projections utilizing different climate models to provide a measure of climate uncertainty.

\subsubsection{Results}

Figure 9 (see Appendix) displays the preliminary median yield projection across climate models using the statistical model described in equation 1 discussed above. Figure 9, panel 2 shows the time series of the yield changes. Yield changes are 


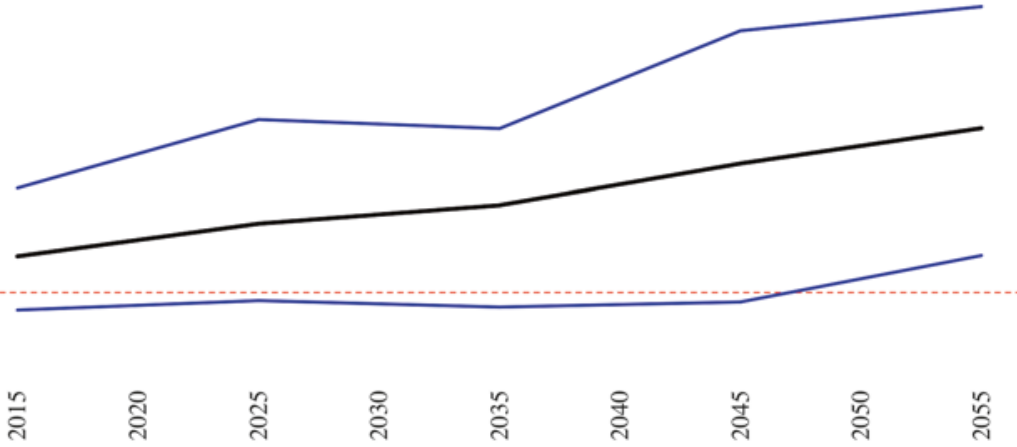

Fig. 5 Time series of forecasted yield impacts (lowland wet rice). Blue lines represent minimum and maximum predicted yields across 14 climate models. Black line represents the median predicted yield change across models. Baseline scenario is that yield trends continue on their current path but temperatures and rainfall patterns continue to follow historical averages

measured relative to a baseline scenario where yields continue on their historical upward trends but where climate conditions continue to vary around their historical averages. The climate scenarios assume the same current yield trends but with changes in climate predicted by GCMs. Because maximum temperature is found to be strongly positively related to higher yields, future yields are predicted to be higher, on average, under climate change. This is likely a result of insufficient observations needed to estimate the historical relationship accurately. Here we find the benefits from rising maximum temperatures outweigh the negatives from rising minimum temperature. In other cases we have found the opposite to be true (Fig. 5).

\section{Summary and Outlook}

Given the extremely limited nature of data in Lao PDR we are hesitant to offer any precise policy recommendations. Our results come from a 6-year panel, which cannot be considered an entirely accurate representation of the historical relationship between climatic variables and yields. This is echoed in our results as we find only three significant effects across all specifications. Moreover, it should also be noted that our results rely on historical data and thus model accuracy is tied to (unobservable) data quality.

In regards to wet season production, we find that a 1-degree increase in daytime temperatures holding all else equal causes an $11.8 \%$ increase in yield. This would suggest that higher daytime temperatures as a result of climate change would in fact be beneficial for rice production in Lao PDR. Furthermore, given that Lao PDR has achieved self-sufficiency in rice production in recent years it appears that the impact 
of climate change on food security does not appear to be a major concern. Although the country appears to have met self-sufficiency at the national level, it is certainly clear that not all households are able to meet rice consumption requirements. According to some estimates, about $30 \%$ of the population has insufficient food for more than 6 months of the year. However, much of this deficiency is in the northern and eastern mountainous areas, while the Mekong River valley is an area of surplus (ADB 2006). Thus, based on our projections, yields in the Mekong River valley will increase as a result of climate change surpluses will be further extended. In regards to policy, marketing of the surplus will be the key policy challenge. According to the LECS only $8 \%$ of all rice produced is sold, and thus extending both domestic and international trade should be made a priority.

Of more concern are the individuals located in the mountainous regions of the country that rely on upland production systems. Our results suggest there is a high level of uncertainty between temperature and yields. For example, we find that an increase of 1 degree in average daytime temperature causes a 38\% increase in yields, while an increase of 1 degree in average nighttime temperature causes a $30 \%$ reduction in yields. These large shocks can be incredibly damaging as individuals engaged in this production system are the most likely to be unable to reach selfsufficiency. Therefore, it appears that one clear policy option would be strategies to reduce variability. Crop diversification is one potential option, although our analysis does not consider other crops so we cannot comment wither there is less variability. Insurance mechanisms that protect against shocks are likely the best option. However, extending any type of insurance to individuals in such remote locations will likely be of extreme difficulty.

We also want to add the caveat that data from upland production systems are likely the most inaccurate. Due to the extremely remote nature of these systems the validity of the data should certainly be taken with a grain of salt. Furthermore, we would like to highlight the limited sample size and subsequent limited power of our results for the upland systems. Thus we offer these recommendations with reservations.

\section{Conclusions and Extensions}

This report adds support to the growing literature estimating the impacts of weather and climate change on rice production. We focus our analysis in Lao PDR, a country whose economy relies on the production of rice, but has had received little analysis on how climate change will impact the sector. This represents a crucial gap in the literature, as rice is instrumental to the Lao economy and will undoubtedly face challenges from climate change.

We use advanced econometric models to first estimate the historical relationship between observed rice yields and climatic variables. With this relationship established, we then downscale projections from the leading climate models to forecast 
the impact on rice yields under these climate scenarios. Our results are consistent with previous work in the region, as we find weak evidence that elevated minimum nighttime temperatures are highly damaging to rice yields. Conversely, we find support that elevated maximum daytime temperatures increase yields. Overall the size of the impact and statistical significance is larger for increased maximum temperatures, suggesting that elevated temperatures might have a net positive impact on rice yields in Lao PDR. Turning next to forecasting, our projections confirm this intuition, as future yields are predicted to be higher, on average, under climate change.

We offer some major caveats to these findings. First, our results are not significant at traditional levels although this not surprising given our limited panel. Our results come from a 6-year panel, which cannot be considered an entirely accurate representation of the historical relationship between climatic variables and yields. Second, there are major data quality issues surrounding rice yields. Although data quality is improving rapidly in Lao PRD, high-resolution rice yield data is only recently available, and is of unknown quality. Given our results rely on this historical data, our model accuracy is tied to the quality of the data. That being said, our results are in line with previous work in the region and serve as a useful preliminary first step to modeling how climate change will impact rice yields in Lao PDR. Over time as data quality improves, these results can be easily replicated to strengthen the analysis.

Disclaimer and Contacts Regional Rice Initiative Research Reports have not been subject to independent peer review and constitute views of the authors only. For comments and/or additional information, please contact:

Sam Heft-Neal and David Roland-Holst

Department of Agricultural and Resource Economics

207 Giannini Hall

University of California Berkeley

CA 94720 - 3310 USA

E-mail: dwrh@berkeley.edu

Drew Behnke

Department of Economics

University of California Santa Barbara

CA, USA

\section{Appendix - Rice Yield Regression Model Results (Figs. 6, 7, 8, and 9)}



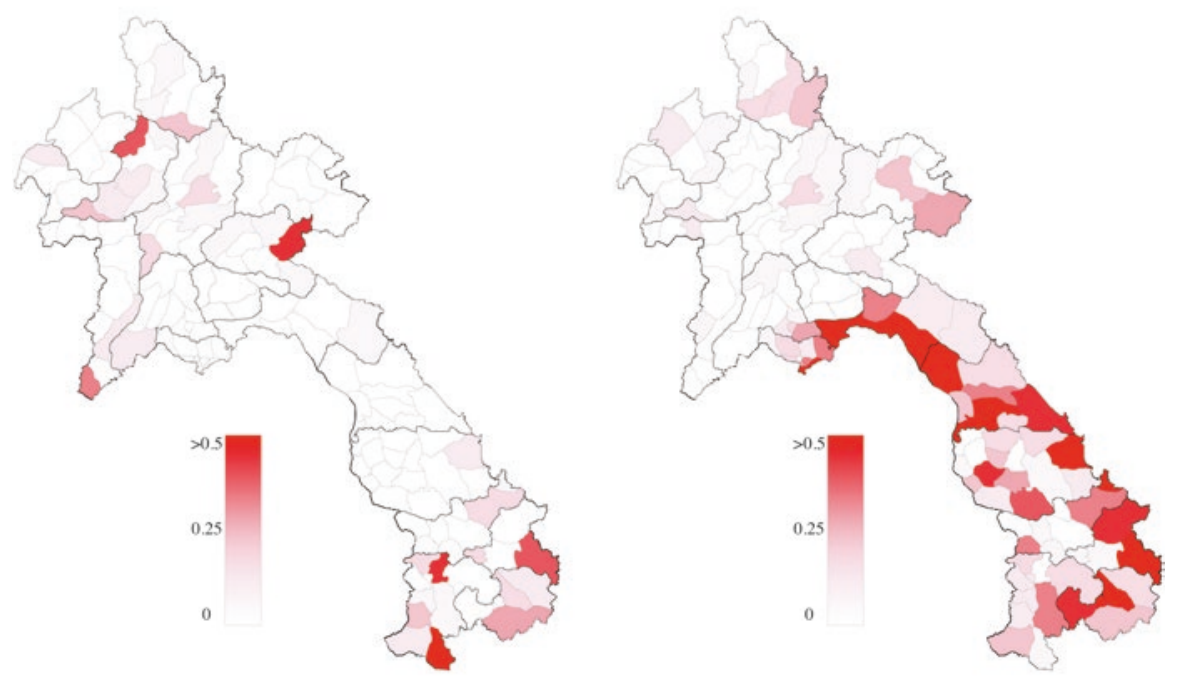

Source: Crop Statistics Yearbook (DOA, Lao PDR)

Fig. 6 Largest rice area losses 2006-2012 by cause. Maps show the maximum wet-season lowland rice area lost from flood or drought in any year over the study period 2006-2012. The figure illustrates that over the seven-year study period a majority of districts experienced some losses from floods or droughts. Flood losses were more common and tended be to more severe with some districts reporting $100 \%$ losses in bad a flood year

Drought

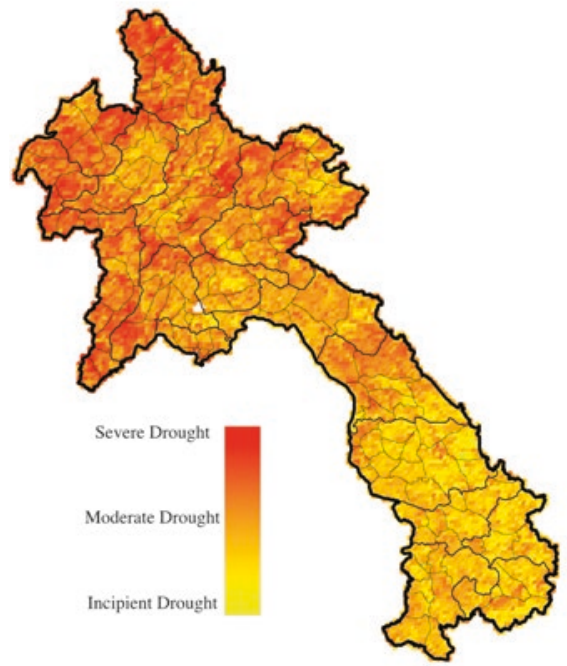

Flood

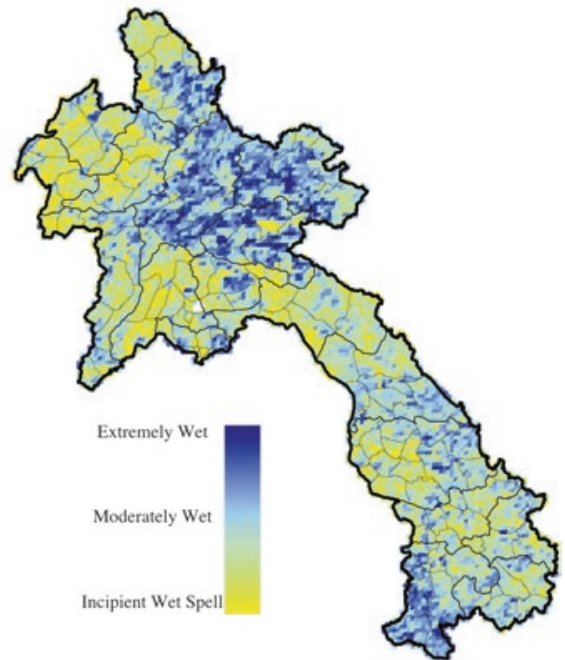

Source: Drought Severity Index (DSI) described in Mu et al (2013)

Fig. 7 Most extreme growing-season weather conditions 2006-2012. Maps show the most extreme dry and wet conditions experienced during the rice-growing season over the study period. Categories correspond to the qualitative categories described in $\mathrm{Mu}$ et al. 


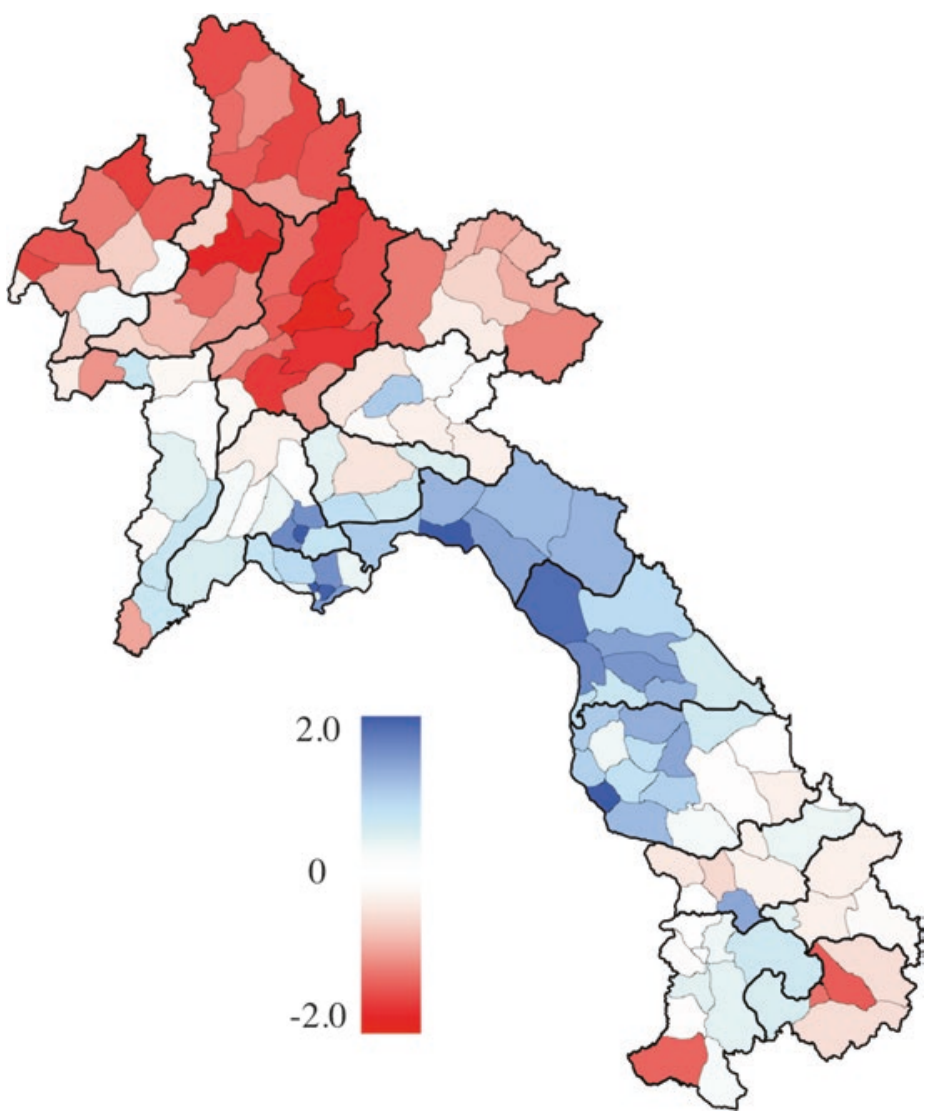

Fig. 8 Average Drought Severity Index (DSI) for rainy season 2004. Average area-weighted DSI values for Lao PDR districts. Blue represents greater than normal and red represents less than normal water levels. This figure is meant to provide an illustration of the data source described in Mu et al. (2013). Data are averaged over rainy season in 2004. Note that the DSI map is roughly an inverse of the precipitation map in Fig. 1 
2015
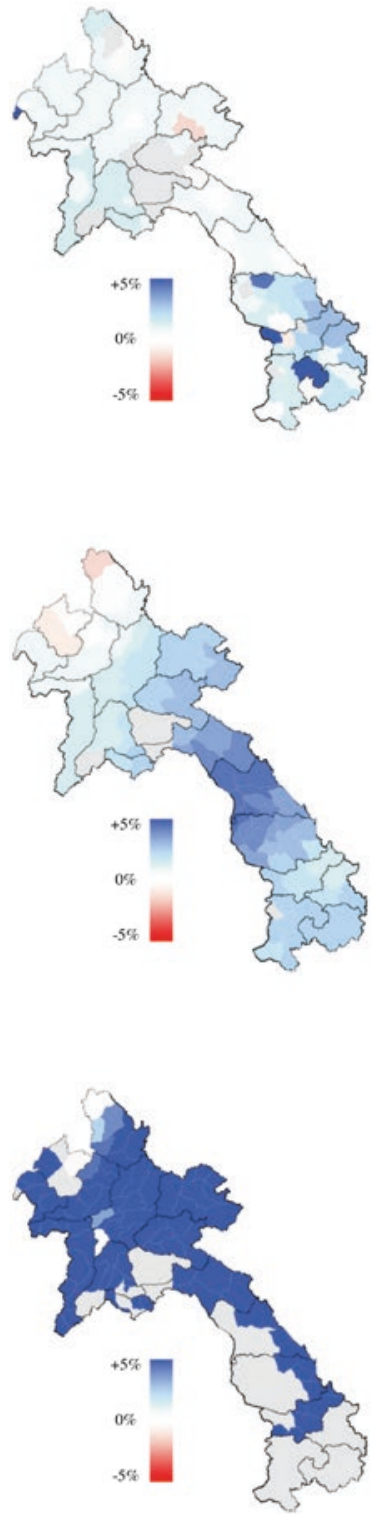

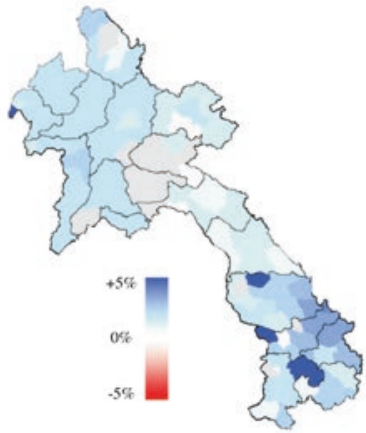

Lowland

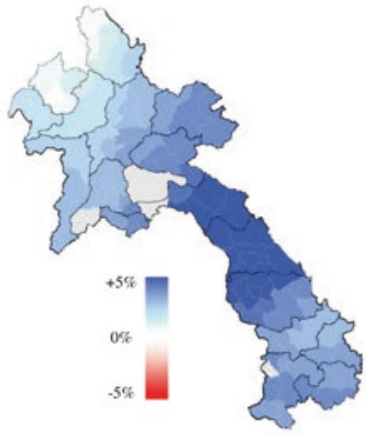

Permanent Upland

2025

2035

Irrigated
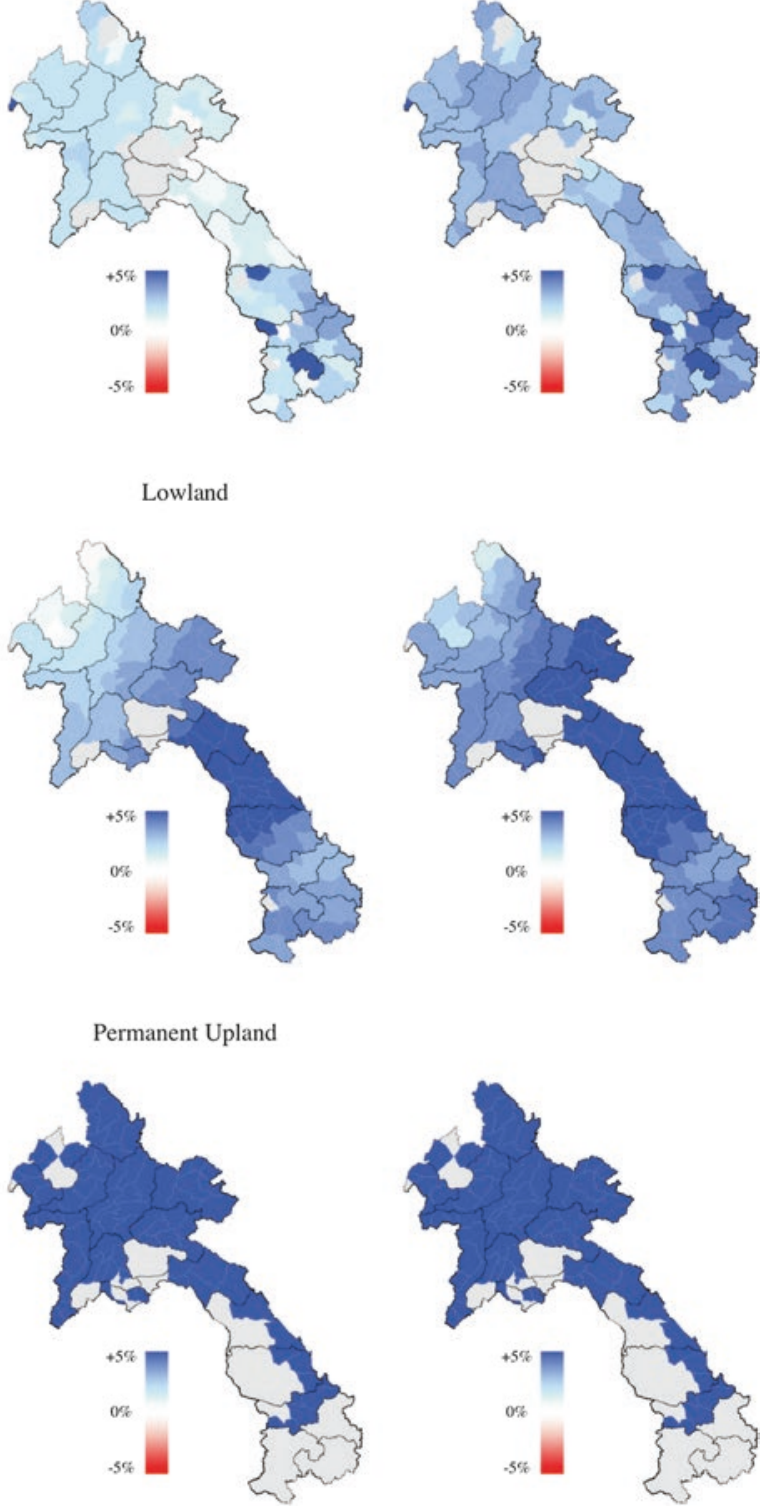

Fig. 9 Preliminary projected yield changes 2015-2035 
Rotary Upland
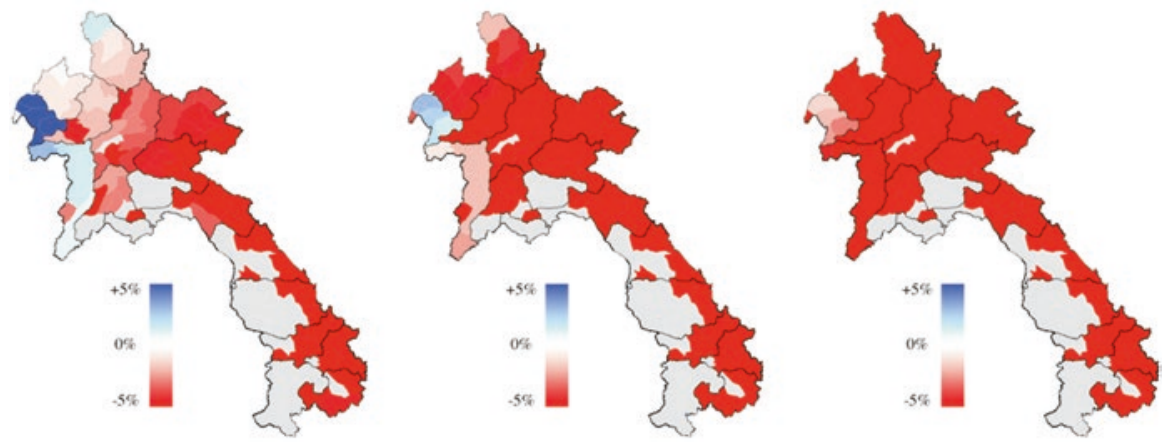

Shifting Upland
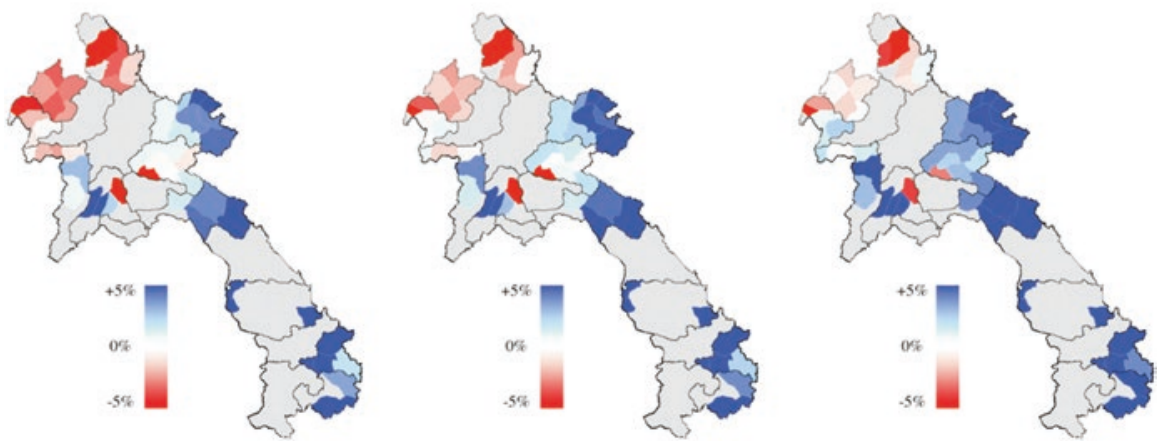

Fig. 9 (continued)

\section{References}

Asian Development Bank (ADB) (2006) "Lao PDR: An Evaluation Synthesis on Rice", Case Study, September 2006.

Belder et al. (2004) - P Belder, B.A.M Bouman, R Cabangon, Lu Guoan, E.J.P Quilang, Li Yuanhua, J.H.J Spiertz, T.P Tuong, Effect of water-saving irrigation on rice yield and water use in typical lowland conditions in Asia, Agricultural Water Management, Volume 65, Issue 3, 2004, Pages 193-210, ISSN 0378-3774.

Borrell, A., A. Garside, and S. Fukai, "Improving efficiency of water use for irrigated rice in a semi-arid tropical environment," Field Crops Research, 1997, 52 (3), 231-248.

Bouman, BAM, T.P. Tuong, E. Humphreys, TP Tuong, and R. Barker. (2007) "Rice and water," Advances in Agronomy, 92, 187-237.

Bouman, BAM, T.P. Tuong, S. Peng, AR Castaneda, and RM Visperas (2005) "Yield and water use of irrigated tropical aerobic rice systems," Agricultural Water Management, 74 (2), 87-105.

Burke, M., Dykema, J., Lobell, D. B., Miguel, E., \& Satyanath, S. (2015). Incorporating climate uncertainty into estimates of climate change impacts. Review of Economics and Statistics, 97(2), 461-471. 
Burke, M., J. Dykema, D. Lobell, E. Miguel, and S. Satyanath, "Incorporating Climate Uncertainty into Estimates of Climate Change Impacts, with Applications to US and African Agriculture," Review of Economics and Statistics, Forthcoming.

DOA (2012) - Department of Agriculture at Ministry of Agriculture and Forestry of the Lao People's Democratic Republic “Crop Statistics Year Book," 2006-2012.

Easterling, D. R., Horton, B., Jones, P. D., Peterson, T. C., Karl, T. R., Parker, D. E., ... \& Folland, C. K. (1997). Maximum and minimum temperature trends for the globe. Science, 277(5324), 364-367.

Homma, K., T. Horie, T. Shiraiwa, S. Sripodok, and N. Supapoj, "Delay of heading date as an index of water stress in rainfed rice in mini-watersheds in Northeast Thailand," Field crops research, 2004, 88 (1), 11-19.

IPCC, "Fourth Assessment Report of the Intergovernmental Panel on Climate Change: The Impacts, Adaptation and Vulnerability (Working Group III)." Cambridge University Press, New York. 2007a.

IPCC. "Summary for Policymakers," in S. Solomon, D. Qin, M. Manning, Z. Chen, M. Marquis, K.B. Averyt, M.Tignor, and H.L. Miller, eds., Climate Change 2007: The Physical Science Basis. Contribution of Working Group I to the Fourth Assessment Report of the Intergovernmental Panel on Climate Change., Cambridge University Press, Cambridge, United Kingdom and New York, NY, USA, 2007b.

Knutti, R., Furrer, R., Tebaldi, C., Cermak, J., \& Meehl, G. A. (2010). Challenges in combining projections from multiple climate models. Journal of Climate, 23(10), 2739-2758.

MAF - Ministry of Agriculture and Forestry of the Lao People's Democratic Republic "Lao People's Democratic Republic Rice Policy Study", Technical Report conducted by the International Rice Research Institute (IRRI), the Food and Agricultural Organization of the United Nations (FAO), and the World Bank, 2012.

Mu, Q., M. Zhao, J. S. Kimball, N. G. McDowell, and S. W. Running. "A remotely sensed global terrestrial drought severity index". Bulletin of the American Meteorological Society, 94(1):8398, 2013.

Lobell, D. B., \& Burke, M. B. (2010). On the use of statistical models to predict crop yield responses to climate change. Agricultural and Forest Meteorology, 150(11), 1443-1452.

Pandey, S., "Economics of Lowland Rice Production in Laos: Opportunities and Challenges" in Increased Lowland Rice Production in the Mekong Region edited by Shu Fukai and Jaya Bansnayake. ACIAR Proceedings 101, 2001.

Peng, S., J. Huang, J. Sheehy, R. Laza, R. Visperas, X. Zhong, G. Centeno, G. Khush, and K. Cassman. 2004. "Rice yields decline with higher night temperature from global warming." Proceedings of the National Academy of Sciences of the United States of America 101:9971.

Sawano, S., T. Hasegawa, S. Goto, P. Konghakote, A. Polthanee, Y. Ishigooka, T. Kuwagata, and $\mathrm{H}$. Toritani, "Modeling the dependence of the crop calendar for rain-fed rice on precipitation in Northeast Thailand," Paddy and Water Environment, 2008, 6 (1), 83-90.

Schiller, J.M., B. Linquist, , K. Douangsila, P. Inthapanya, B. Douang Boupha, S. Inthavong, and P. Sengxua "Constraints to Rice Production Systems in Lao" in Increased Lowland Rice Production in the Mekong Region edited by Shu Fukai and Jaya Bansnayake. ACIAR Proceedings 101, 2001.

Schlenker, W. and M.J. Roberts, "Nonlinear temperature effects indicate severe damages to US crop yields under climate change," Proceedings of the National Academy of Sciences, 2009, 106 (37), 15594.

Sharma, P. K., Pantuwan, G., Ingram, K. T., \& De Datta, S. K. (1994). Rainfed lowland rice roots: soil and hydrological effects. Rice Roots Nutrient and Water Use. IRRI, Manila, 55.

Sheehy, J., P. Mitchell, and A. Ferrer. 2006. "Decline in rice grain yields with temperature: Models and correlations can give different estimates." Field crops research 98:151-156.

Wade, L. J., Fukai, S., Samson, B. K., Ali, A., \& Mazid, M. A. (1999). Rainfed lowland rice: physical environment and cultivar requirements. Field Crops Research, 64(1), 3-12. 
Wassmann, R., S. Heuer, A. Ismail, E. Redona, R. Serraj, RK Singh, G. Howell, H. Pathak, and K. Sumfleth, "Climate change affecting rice production: the physiological and agronomic basis for possible adaptation strategies," Advances in Agronomy, 2009a, 101, 59-122.

Wassmann, R., SVK Jagadish, K. Sumfleth, H. Pathak, G. Howell, A. Ismail, R. Serraj, E. Redona, RK Singh, and S. Heuer, "Regional vulnerability of climate change impacts on Asian rice production and scope for adaptation," Advances in Agronomy, 2009b, 102, 91-133.

Welch, J., J. Vincent, M. Auffhammer, P. Moya, A. Dobermann, and D. Dawe. 2010. "Rice yields in tropical/subtropical Asia exhibit large but opposing sensitivities to minimum and maximum temperatures." Proceedings of the National Academy of Sciences 107:14562.

$\mathrm{Xu}$, Kenong, and David J. Mackill. "A major locus for submergence tolerance mapped on rice chromosome 9." Molecular Breeding 2.3 (1996): 219-224.

Yatagai, Akiyo, Kenji Kamiguchi, Osamu Arakawa, Atsushi Hamada, Natsuko Yasutomi, and Akio Kitoh. "APHRODITE: Constructing a long-term daily gridded precipitation dataset for Asia based on a dense network of rain gauges." Bulletin of the American Meteorological Society 93, no. 9 (2012): 1401-1415.

Yin, X., M.J. Kropff, and Goudriaan J., "Differential effects of day and night temperature on development to flowering in rice," Annals of Botany, 1996, 77 (3), 203-213.

Yoshida, S., Fundamentals of rice crop science, Int. Rice Res. Inst., 1981.

Open Access This chapter is distributed under the terms of the Creative Commons AttributionNonCommercial-ShareAlike 3.0 IGO license (https://creativecommons.org/licenses/by-nc-sa/3.0/ igo/), which permits any noncommercial use, duplication, adaptation, distribution, and reproduction in any medium or format, as long as you give appropriate credit to the Food and Agriculture Organization of the United Nations (FAO), provide a link to the Creative Commons license and indicate if changes were made. If you remix, transform, or build upon this book or a part thereof, you must distribute your contributions under the same license as the original. Any dispute related to the use of the works of the FAO that cannot be settled amicably shall be submitted to arbitration pursuant to the UNCITRAL rules. The use of the FAO's name for any purpose other than for attribution, and the use of the FAO's logo, shall be subject to a separate written license agreement between the FAO and the user and is not authorized as part of this CC-IGO license. Note that the link provided above includes additional terms and conditions of the license.

The images or other third party material in this chapter are included in the chapter's Creative Commons license, unless indicated otherwise in a credit line to the material. If material is not included in the chapter's Creative Commons license and your intended use is not permitted by statutory regulation or exceeds the permitted use, you will need to obtain permission directly from the copyright holder.

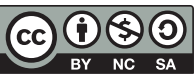

